(c) American Dairy Science Association, 2005.

\title{
Small-Scale Manufacture of Process Cheese Using a Rapid Visco Analyzer
}

R. Kapoor and L. E. Metzger

MN-SD Dairy Foods Research Center, Department of Food Science and Nutrition, University of Minnesota, St. Paul 55108

\begin{abstract}
Numerous formulation and processing parameters influence the functional properties of process cheese. Recently, a small-scale ( $25 \mathrm{~g}$ ) manufacturing and analysis method was developed using a rapid visco analyzer (RVA), which was designed to evaluate the functional properties of process cheese when subjected to various formulations and processing conditions. Although this method successfully manufactured process cheese, there was a significant difference in the functional properties of the process cheese compared with process cheese manufactured on a pilot scale. In the present study, adjustments in the RVA methodology involving the RVA processing conditions, preblend preparation, and texture profile analysis (TPA) techniques for the final process cheese were investigated. Fourteen samples of pasteurized processed cheese food (PCF) were manufactured from 14 different preblends. Each preblend was prepared using 1 of the 14 different natural cheeses and was balanced for moisture, fat, and salt. Each of these 14 preblends was split into 3 portions and each portion was subjected to 3 different manufacturing treatments. The first treatment was manufactured in a pilot-scale Blentech twin screw (BTS) cooker, and the remaining 2 treatments were manufactured in an RVA with different processing profiles. The RVA treatments were produced in triplicate. The resulting process cheeses were analyzed for moisture and functional properties. Texture profile analysis and RVA melt analyses were performed on all PCF treatments. Additionally, for the RVA treatments, the data for time of emulsification and end apparent viscosity during RVA manufacture were collected and recorded. The functional properties of the PCF manufactured using the RVA treatments showed good correlation with the functional properties of the PCF produced on the pilot scale. Additionally, the end apparent viscosity during RVA manufacture was correlated with the functional properties
\end{abstract}

Received April 29, 2005.

Accepted June 13, 2005.

Corresponding author: Lloyd E. Metzger; e-mail: lmetzger@ umn.edu. of the process cheese. Consequently, the RVA can be used as a small-scale manufacturing and analysis tool for predicting the functional properties of process cheese, and for evaluating how various formulations and processing parameters affect these functional properties. Moreover, the adjustments in the RVA methodology produced process cheese with functionality similar to process cheese produced in the BTS.

(Key words: process cheese, rapid visco analyzer)

Abbreviation key: BTS = Blentech twin-screw pilotscale cooker, $\mathbf{P C}=$ pasteurized process cheese, $\mathbf{P C F}=$ pasteurized process cheese food, $\mathbf{R V A}=$ rapid visco analyzer, TPA = texture profile analysis.

\section{INTRODUCTION}

Process cheese is a generic term used to describe 3 separate categories of cheese. These categories are pasteurized process cheese (PC), pasteurized process cheese food (PCF), and pasteurized process cheese spread (Code of Federal Regulations, 2003). Functional properties such as meltability and textural properties are important attributes that influence the quality and end use of process cheese (Zehren and Nusbaum, 2000; Lucey et al., 2003). Process cheese is used in several forms (slices, blocks, shreds, and sauces) and as an ingredient in numerous products. Consequently, the required functional properties (unmelted texture and melting properties) are unique for each process cheese end-use application.

Researchers have highlighted that the ingredients used in a formulation, as well as the processing conditions, significantly influence the functional properties of process cheese. The type and amount of natural cheese, emulsifying salts, and the other ingredients used have an influence on its functional properties (Thomas, 1973; Gupta et al., 1984; Caric et al., 1985; Zehren and Nusbaum, 2000). Studies have indicated that as the level of intact casein or calcium and phosphate increase in natural cheese, the firmness of the resulting process cheese increases and its meltability decreases (Vakaleris et al., 1962; Sood et al., 1979; Berger et al., 1998; Piska and Štětina, 2003). Moreover, 
the intrinsic parameters of the final process cheese such as $\mathrm{pH}$ also affect the functional properties of process cheese (Marchesseau et al., 1997; Lee and Klostmeyer, 2001). Processing conditions such as cook temperature, cook time, the amount of shear applied during manufacture, and the rate at which the process cheese is cooled after manufacture also play a major role in controlling emulsion formation and the resulting functional properties of process cheese (Rayan et al., 1980; Berger et al., 1998; Glenn et al., 2003; Piska and Štětina, 2003; Zong et al., 2004).

Moreover, process cheese manufacturers use various types of cookers with different designs and operating conditions to manufacture process cheese. These cookers differ on the basis of the mode of process cheese production (batch or continuous production), the type of mixing and agitating systems involved, as well as the type and mechanism of heating (indirect heating or direct steam injection) (Berger et al., 1998; Zehren and Nusbaum, 2000). Two common types of batch cookers use single/twin screw augers or high-speed cutting blades. The single or twin screw auger cookers operate at low mixing speeds ranging from 50 to $150 \mathrm{rpm}$ with product temperatures ranging from 70 to $90^{\circ} \mathrm{C}$ for 3 to $7 \mathrm{~min}$. The high-speed cutting blade-type cookers operate at 1500 to $3000 \mathrm{rpm}$ at 95 to $>100^{\circ} \mathrm{C}$ for 2 to 5 min. Recently, an additional cooker called the Rota Therm continuous cooker (Gold Peg International Pty Ltd., Victoria, Australia) has been developed and is being used extensively for process cheese manufacture. This cooker operates at a high mixing speed (600 to $1000 \mathrm{rpm}$ ) with temperatures above $90^{\circ} \mathrm{C}$ and a residence time of approximately 30 to $40 \mathrm{~s}$. Consequently, due to the differences in cooker designs and operating conditions, a specific ingredient blend may not produce process cheese with the same functional properties when manufactured in any of the 3 mentioned cookers. However, by adjusting the major processing parameters such as cook temperature, cook time, and mixing speed, it may be possible to produce process cheese with similar functional properties using 2 different cookers.

Because of the numerous formulation and processing parameters that influence the functional properties of process cheese, manufacturers often struggle to produce process cheese with targeted product characteristics. The differences in cooker designs, mechanism of operation, and processing profiles make it difficult for manufacturers to select an appropriate processing profile for their specific ingredient blend, and to target final process cheese properties. To solve this problem a method for manufacturing and the subsequent analysis of process cheese in 25-g batches using a rapid visco analyzer (RVA) was developed (Metzger et al., 2002; Kapoor et al., 2004). The RVA is a computer-integrated instrument developed by Newport Scientific (Warriewood, Australia) to determine the viscous properties of cooked starch, grain, batters, and other foods. The RVA can measure apparent viscosity over variable mixing speeds and temperature as defined by the operator. This method was designed to facilitate a rapid and inexpensive assessment of how various formulations and processing conditions affect process cheese characteristics. Not only could this system be used to analyze different cooking profiles, but it could facilitate selection of a manufacturing profile that best suits a particular cooker design and produce process cheese with the targeted functional properties.

Kapoor et al. (2004) performed a study wherein they manufactured PC and PCF in the RVA (25-g batches) and compared the final functional properties to process cheese manufactured on a pilot-scale twin-screw process cheese cooker (4.5-kg batches). In the methodology described by Kapoor et al. (2004), after the process cheese was manufactured in the RVA, the molten cheese was transferred into copper cylinders $(20 \mathrm{~mm}$ diameter $\times 30 \mathrm{~mm}$ height) and cooled. The cheese was then removed from the cylinders and the unmelted textural properties of the cheese were measured with texture profile analysis (TPA). Breene (1975) defines TPAhardness as a measure of the unmelted texture of a cheese that describes the firmness of the cheese. Finally, the process cheese was ground and melted in the RVA to assess its melting properties, including hot apparent viscosity and time at $5000 \mathrm{cP}$, as described by Prow (2004).

Prow (2004) and Prow and Metzger (2005) used the RVA to evaluate the melted textural properties of process cheese and process cheese spreads. Prow (2004) performed melt analysis on 18 commercial samples of block process cheese using various melt tests including the RVA and showed that the RVA melting properties of the process cheeses (hot apparent viscosity and time at $5000 \mathrm{cP}$ ) showed a high correlation with process cheese melt temperature as determined by dynamic stress rheometry ( 0.82 and 0.85 , respectively), and also showed a good correlation with the Schreiber melt test ( 0.60 and 0.65 , respectively).

The results of our previous study (Kapoor et al., 2004) indicated that the RVA could be used as an effective tool for the small-scale production and subsequent analysis of process cheese. However, the functionality results (TPA-hardness and hot apparent viscosity) from that study showed that PC and PCF produced in the RVA were significantly different from the $\mathrm{PC}$ and $\mathrm{PCF}$ produced on the pilot scale. These differences may be related to how the ingredients were blended before the cheese was manufactured in the RVA and the pilot 
Table 1. Detailed ingredient blend used to prepare the 14 pasteurized process cheese food (PCF) formulations.

\begin{tabular}{|c|c|c|c|c|c|c|c|c|c|c|c|c|c|c|}
\hline \multirow{2}{*}{$\begin{array}{l}\text { Ingredients, } \\
\%\end{array}$} & \multicolumn{14}{|c|}{ PCF } \\
\hline & 1 & 2 & 3 & 4 & 5 & 6 & 7 & 8 & 9 & 10 & 11 & 12 & 13 & 14 \\
\hline Cheese & 68.0 & 70.9 & 70.8 & 72.5 & 73.8 & 70.0 & 74.8 & 68.8 & 72.0 & 73.1 & 71.0 & 71.1 & 73.4 & 74.1 \\
\hline Butter oil & 0.05 & 0.02 & 0.01 & 0.03 & - & 0.54 & 0.08 & - & - & - & - & 0.62 & - & - \\
\hline Salt & 0.28 & 0.6 & 0.67 & 0.24 & 0.65 & - & 0.66 & 0.18 & 0.72 & 0.48 & 0.01 & 0.66 & 0.39 & 0.55 \\
\hline $\mathrm{TSC}^{1}$ & 2.5 & 2.5 & 2.5 & 2.5 & 2.5 & 2.5 & 2.5 & 2.5 & 2.5 & 2.5 & 2.5 & 2.5 & 2.5 & 2.5 \\
\hline Water & 22.1 & 19.4 & 18.6 & 17.8 & 16.6 & 19.1 & 14.5 & 21.3 & 17.6 & 16.4 & 19.5 & 17.6 & 16.2 & 15.1 \\
\hline
\end{tabular}

${ }^{1} \mathrm{TSC}=$ Trisodium citrate.

plant, or how the samples from each of the 2 treatments were prepared for TPA analysis (Kapoor et al., 2004).

The objective of this study was to develop manufacturing protocols for RVA-based process cheese manufacture that would produce process cheese with similar functional characteristics compared with process cheese manufactured on a pilot scale. This study also evaluated whether the data obtained during RVA manufacture could be used to predict the final functional properties of the process cheese.

\section{MATERIALS AND METHODS}

\section{Experimental Design}

Fourteen PCF formulations (preblends) utilizing 14 different natural cheeses were prepared. After preparation, each preblend was split into 3 portions and each portion was subjected to 3 different manufacturing treatments: pilot scale Blentech twin-screw pilot-scale cooker (BTS; Blentech Corporation, Rohnert Park, CA), RVA-treatment 1 (RVA-1) and RVA-treatment 2 (RVA2). Each of the $14 \mathrm{PCF}$ formulations was produced in triplicate for RVA-1 and RVA-2 and singly for the BTS treatment.

\section{Process Cheese Formulation}

All of the PCF formulations were developed using Techwizard, which is an Excel-based formulation software program (Metzger, 2003) provided by Owl Software (2301 Wood Street, Lancaster, PA). The detailed ingredient blend and formulations of the $14 \mathrm{PCF}$ are shown in Table 1. The formulation software was used to balance the moisture, fat, and salt to $43.0,25.0$, and $2.0 \%$, respectively.

The 14 natural cheeses that were used in the PCF formulations were manufactured using a variety of protocols that resulted in a range of calcium, phosphorus, lactose, and salt-in-moisture levels. These natural cheeses were ripened for 2 mo before they were used in each PCF formulation. The compositional differences of the natural cheeses resulted in differences in their physicochemical properties such as bound calcium and phosphate, $\mathrm{pH}$, and the rate of protein breakdown (amount of intact casein) (Upreti et al., 2004).

The emulsifying salt used in each formulation was trisodium citrate (duohydrate) (Archer Daniels Midland Company, Decatur, IL). Other ingredients included: nonfat dried milk (low heat) (Dairy America, Fresno, CA), anhydrous butter oil (MidAmerica farms, Springfield, MO), salt, and water.

\section{Process Cheese Manufacture}

Preblend preparation. A preblend of each of the 14 PCF formulations was prepared by mixing all the ingredients, including natural cheese $(4.5-\mathrm{kg}$ batch total) in a Blentech twin-screw pilot-scale cooker (Blentech Corporation) at $50 \mathrm{rpm}$ for $30 \mathrm{~min}$ at room temperature to achieve a homogeneous paste. This was followed by removing $300 \mathrm{~g}$ of the prepared preblend, which was then used in the 2 RVA processing treatments. The remaining preblend was held in the pilot-scale cooker and subjected to the BTS treatment.

RVA-small-scale manufacture. A 25-g portion of the preblend was weighed into 6 RVA canisters, and $0.6 \mathrm{~g}$ of water was added to compensate for moisture loss during manufacture in the RVA. This was followed by inserting an RVA paddle in each of the canisters and sealing the canisters with plastic wrap. The sealed RVA canisters were tempered in a water bath at $40^{\circ} \mathrm{C}$ for 10 min before being manufactured in the RVA. For treatment 1, 3 of the RVA canisters were subjected to a temperature of $80^{\circ} \mathrm{C}$ and a stirring speed of $450 \mathrm{rpm}$ for 6 min (Figure 1). For treatment 2, the remaining 3 RVA canisters were subjected to a temperature of $95^{\circ} \mathrm{C}$ and a stirring speed of $1000 \mathrm{rpm}$ for $2 \mathrm{~min}$ (Figure 2). In the RVA treatments, the time at which an increase in viscosity was observed during manufacture was recorded and reported as the time of emulsification (Kapoor et al., 2004). Additionally, in both the RVA processing treatments, the cooked PCF was mixed for an 


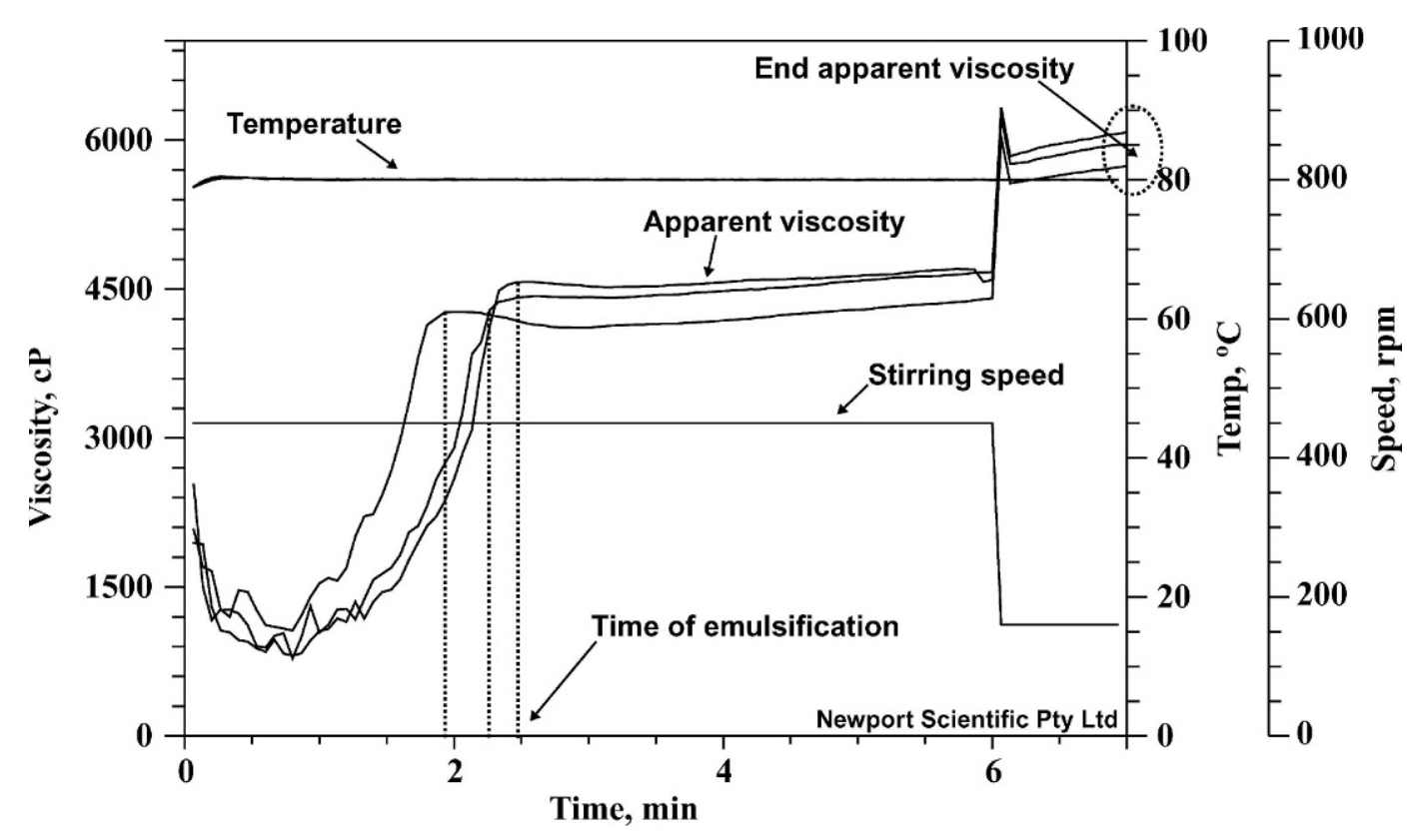

Figure 1. Typical apparent viscosity profile obtained during manufacture (triplicate manufacture of one of the pasteurized process cheese food treatments is indicated) of pasteurized process cheese food (PCF) using the rapid visco analyzer - treatment 1 (RVA-1) manufacturing profile. The dotted lines indicate the time of emulsification and the highlighted circle (towards the end of manufacture) indicates the end apparent viscosity value. Stirring speed, temperature, and apparent viscosity are identified on the figure.

additional minute at $160 \mathrm{rpm}$ to obtain the end apparent viscosity data, which was also recorded (Figures 1 and 2). After manufacture, the process cheeses were transferred to copper cylinders $(20 \mathrm{~mm}$ diameter and $30 \mathrm{~mm}$ height). The cylinders were sealed with plastic wrap and tempered at room temperature for $15 \mathrm{~min}$.

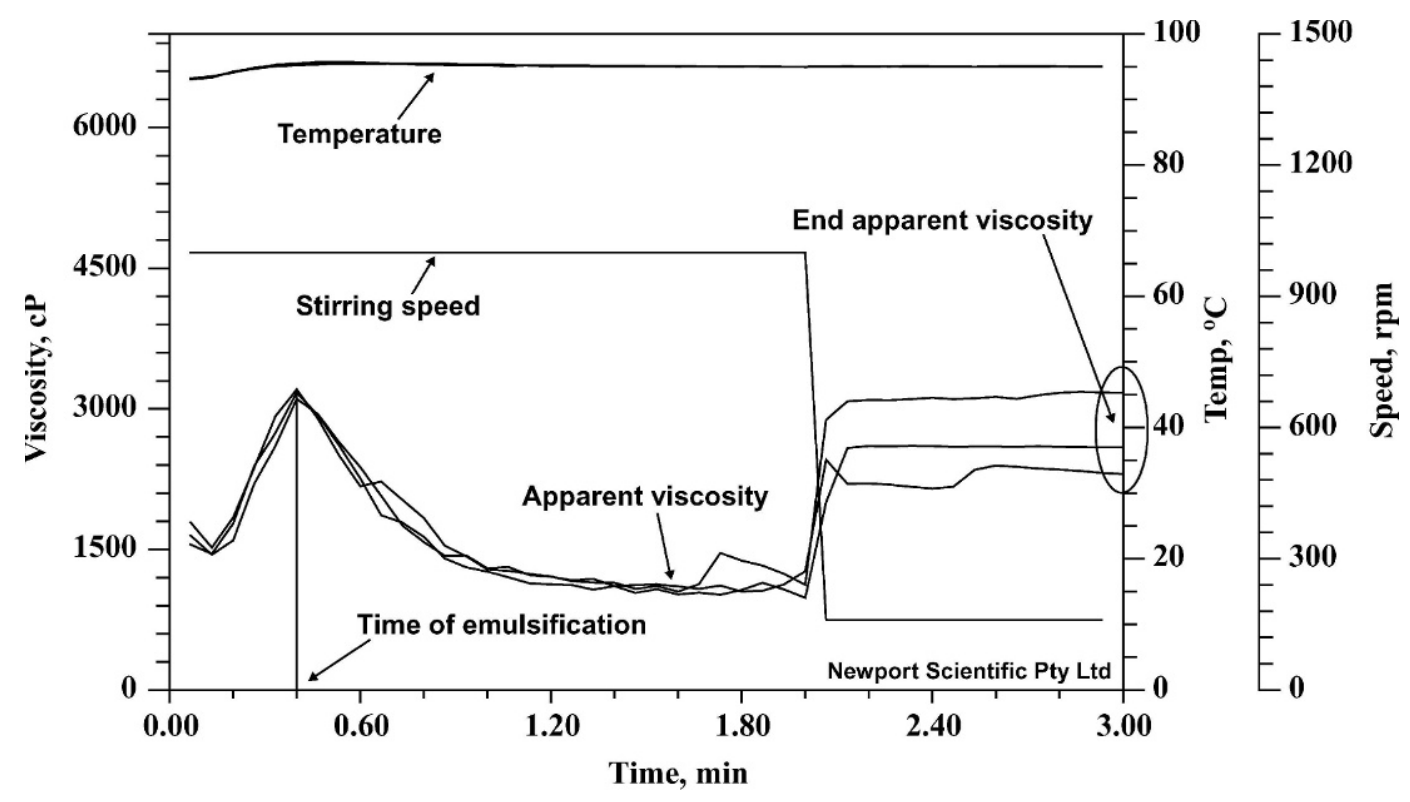

Figure 2. Typical apparent viscosity profile obtained during manufacture (triplicate manufacture of one of the pasteurized process cheese food treatments is indicated) of pasteurized process cheese food (PCF) using the rapid visco analyzer - treatment 2 (RVA-2) manufacturing profile. The vertical line indicates the time of emulsification and the highlighted circle (towards the end of manufacture) indicates the end apparent viscosity values. Stirring speed, temperature, and apparent viscosity are identified on the figure. 
After $15 \mathrm{~min}$, the cylinders were transferred to a cold room and stored at $4^{\circ} \mathrm{C}$ until further analysis was completed.

Pilot-plant manufacture. The remaining preblend that was held in the Blentech twin-screw cooker blender (Blentech Corporation) was subjected to pilot-plant PCF manufacture. The temperature of the preblend was increased to $80^{\circ} \mathrm{C}$ in approximately $5 \mathrm{~min}$ and held for an additional $5 \mathrm{~min}$. The auger speed throughout the heating and holding stages was $140 \mathrm{rpm}$. A portion of the cooked PCF was used to fill 3 copper cylinders (20 mm diameter and $30 \mathrm{~mm}$ height) and used for TPA analysis. The cylinders were sealed with plastic wrap and transferred to the cold room $\left(4^{\circ} \mathrm{C}\right)$ after $15 \mathrm{~min}$. The remaining PCF was used to fill $1-\mathrm{kg}$ boxes and transferred to a cold room $\left(4^{\circ} \mathrm{C}\right)$ after $15 \mathrm{~min}$. All the cooked process cheeses were stored at $4^{\circ} \mathrm{C}$ until further analysis was completed.

\section{Composition and Functional Analysis}

The moisture content of all 14 PCF produced with the 3 processing treatments were analyzed in duplicate using a vacuum oven as described by Bradley and Vanderwarn (2001).

For TPA analysis, the cylinders of PCF $(20 \mathrm{~mm} \times 30$ $\mathrm{mm}$ ) that were filled during manufacture were removed from the copper molds and cut to a height of $20 \mathrm{~mm}$. Texture profile analysis was performed using a TA.XT2 Texture Analyzer (Texture Technologies Corp., Scarsdale, NY; Stable Microsystems, Godalming, UK) as described by Drake et al. (1999). The test conditions were as follows: uniaxial 2-bite compression, $50 \mathrm{~mm}$ diameter cylindrical flat probe (TA-25); compression, 80\%; and crosshead speed, $0.8 \mathrm{~mm} / \mathrm{s}$. Process cheese was analyzed for TPA-hardness as described by Breene (1975). Texture profile analysis was performed in triplicate on the 3 PCF-filled cylinders for all 3 manufacturing treatments (BTS, RVA-1, and RVA-2).

The RVA melt test was performed on all 3 treatments for the 14 PCF. The test continuously measured the apparent viscosity during a heating, holding, and cooling profile described by Prow (2004). In the RVA melt test, a 14-g sample of process cheese was ground and weighed into an RVA canister, along with $1 \mathrm{~g}$ of propylene glycol. For the RVA manufacturing treatments (RVA-1 and RVA-2), the process cheese sample remaining from the TPA was ground and used for the RVA melt test. The RVA melt test was performed in triplicate on the 2 RVA manufacturing treatments. For the BTS (pilot-scale) treatment, a representative sample was cut from the 1-kg blocks, ground, and used for RVA melt test. The RVA melt test for BTS treatment was performed in duplicate. The RVA melt test was performed by raising the temperature of the canister from $25^{\circ} \mathrm{C}$ to a peak temperature of $85^{\circ} \mathrm{C}$ in $5 \mathrm{~min}$, holding for $3 \mathrm{~min}$ at the peak temperature, and finally cooling to $25^{\circ} \mathrm{C}$ in $6 \mathrm{~min}$. The stirring speed was held at $0 \mathrm{rpm}$ for $30 \mathrm{~s}, 20 \mathrm{rpm}$ for $30 \mathrm{~s}, 100 \mathrm{rpm}$ for $1 \mathrm{~min}$, and $300 \mathrm{rpm}$ for the remainder of the test. The minimum apparent viscosity during the holding period and the time required to reach an apparent viscosity of 5000 $\mathrm{cP}$ during the cooling period were collected from the apparent viscosity vs. time curve. These data points collected during RVA melt analysis are referred to as hot apparent viscosity and time at $5000 \mathrm{cP}$, respectively (Prow, 2004). According to Prow (2004), the hot apparent viscosity is a measure of how well a cheese flows at a fixed temperature; the time at $5000 \mathrm{cP}$ is a measure of how quickly a melted cheese solidifies during cooling. Therefore, process cheese with a high Schreiber melt area or a low dynamic stress rheometry melting temperature will show a low hot apparent viscosity and a long time at $5000 \mathrm{cP}$ in the RVA melt test.

\section{Statistical Analyses}

One-way ANOVA with the 3 manufacturing treatments (BTS, RVA-1, and RVA-2) as the factor was performed to obtain the $P$-values for all the functional properties using Macanova (version 4.12, School of Statistics, University of Minnesota, St. Paul). Paired comparison using Fisher's LSD was performed to compare the 3 functional properties of the 14 PCF manufactured from the 3 manufacturing treatments. The comparisons were made at a 0.05 level of significance and the results were considered significant at $P<0.05$. Simple linear regression analysis was performed to determine how well the functional properties of the RVA treatments correlated with the BTS (pilot-scale) treatment. Additionally, simple linear regression analysis was performed to determine how well the data collected during RVA manufacture (time of emulsification and end apparent viscosity) correlated with the functional properties of the cheese.

To evaluate and compare the repeatability of the RVA and BTS manufacturing treatments, relative standard deviations (RSD) or relative deviations (RD) were calculated for all 14 PCF. These values were calculated with the following formula: RSD or RD = (standard deviation/mean) $\times 100$.

\section{RESULTS AND DISCUSSION}

\section{Process Cheese Properties}

The mean values for moisture from the 14 PCF produced with the 3 manufacturing treatments (BTS, RVA- 
Table 2. The mean moisture $(n=2)$ of the 14 pasteurized process cheese foods (PCF) manufactured using the 3 manufacturing treatments.

\begin{tabular}{llll}
\hline & \multicolumn{3}{c}{ Moisture, \% } \\
\cline { 2 - 4 } PCF & BTS $^{1}$ & RVA-1 $^{2}$ & RVA-2 $^{3}$ \\
\hline 1 & 43.2 & 43.4 & 43.6 \\
2 & 43.1 & 44.1 & 43.6 \\
3 & 43.4 & 44.2 & 44.0 \\
4 & 42.1 & 42.3 & 42.2 \\
5 & 43.2 & 43.6 & 43.6 \\
6 & 43.1 & 43.8 & 43.5 \\
7 & 42.2 & 43.0 & 42.8 \\
8 & 43.0 & 43.3 & 43.0 \\
9 & 42.8 & 43.3 & 42.9 \\
10 & 43.0 & 43.4 & 43.3 \\
11 & 42.9 & 43.4 & 43.9 \\
12 & 42.8 & 43.5 & 42.8 \\
13 & 42.4 & 42.9 & 43.4 \\
14 & 43.1 & 43.8 & \\
\hline
\end{tabular}

${ }^{1} \mathrm{BTS}=$ Blentech twin-screw pilot-scale cooker.

${ }^{2}$ RVA-1 = Rapid visco analyzer-treatment 1.

${ }^{3}$ RVA-2 = Rapid visco analyzer-treatment 2.

1, and RVA-2) are indicated in Table 2. The average values for the final functional properties of BTS, RVA1 , and RVA-2, including TPA-hardness, hot apparent viscosity, and the time at $5000 \mathrm{cP}$ for all $14 \mathrm{PCF}$, along with the overall means are indicated in Table 3 . The fat, total calcium, total phosphorus, total protein, and $\mathrm{pH}$ of all 14 PCF manufactured using the BTS treat- ment were also measured. There were differences observed in the total calcium, total phosphorus, and $\mathrm{pH}$ of the $14 \mathrm{PCF}$, which highlights the importance of the effect of chemical properties of the process cheese on its functional properties. Because the objective of the present study was to compare the process cheese manufacture in the RVA to pilot-scale process cheese manufacture, the data on the chemical composition of the 14 PCF have not been included and will be discussed in a subsequent paper.

Comparison of the 2 RVA manufacturing treatments. There were no significant differences $(P>0.05)$ in the overall mean TPA-hardness, hot apparent viscosity, and time at $5000 \mathrm{cP}$ values for the $14 \mathrm{PCF}$ manufactured with RVA treatments 1 and 2 (Table 3). Figure 3 indicates the simple linear regression curves (along with the $\mathrm{R}^{2}$ value) between RVA- 1 and RVA-2 for each of the 3 functional properties (TPA-hardness, hot apparent viscosity, and time at $5000 \mathrm{cP}$ ). Consequently, reducing the time of manufacture when the temperature and the mixing speed of a particular cooker are high will produce process cheese with the same functional properties as a cooker operating at low temperature and low mixing speed. Therefore, appropriate modifications in the processing parameters (temperature, time, and mixing speed) can produce process cheese with similar functional properties when different types of cookers are used.

Table 3. Average values of the functional properties along with $\operatorname{RSD}^{1}\left(\mathrm{n}=3\right.$ ) or $\mathrm{RD}^{2}$ (in parentheses; $\left.\mathrm{n}=2\right)$ and the overall means $(\mathrm{n}=14$ ) for the 14 pasteurized process cheese food (PCF) manufactured using the 3 manufacturing treatments.

\begin{tabular}{|c|c|c|c|c|c|c|c|c|c|c|}
\hline \multirow[b]{2}{*}{ PCF } & \multicolumn{3}{|c|}{ TPA-Hardness, $\mathrm{N}$} & \multicolumn{4}{|c|}{ Hot apparent viscosity, $\mathrm{cP}$} & \multicolumn{3}{|c|}{ Time at $5000 \mathrm{cP}, \mathrm{min}$} \\
\hline & $\mathrm{BTS}^{3}$ & $\mathrm{RVA}^{-1} \mathrm{1}^{4}$ & RVA- $2^{5}$ & BTS & & RVA-1 & RVA-2 & BTS & RVA-1 & RVA-2 \\
\hline 1 & $120(2.1)$ & $117(5.8)$ & $141(3.2)$ & 730 & $(2.0)$ & $601(10.4)$ & $609(4.5)$ & $11.33(0.0)$ & $11.27(0.6)$ & $11.27(0.6)$ \\
\hline 3 & $88(3.6)$ & $96(10.2)$ & $93(1.4)$ & 542 & $(5.0)$ & $458(2.1)$ & $448(2.3)$ & $11.64(0.4)$ & $11.73(0.0)$ & $11.67(0.0$ \\
\hline 4 & $98 \quad(9.0)$ & $100(5.3)$ & $94 \quad(0.7)$ & 778 & $(0.9)$ & $531(0.9)$ & $551(5.3)$ & $11.24(0.4)$ & $11.49(0.3)$ & $11.40(0.6$ \\
\hline 5 & $58(5.1)$ & $58(1.1)$ & $55(5.7)$ & 488 & (0.1) & $373(1.9)$ & 339 (4.6) & $11.67(0.0)$ & $11.87(0.0)$ & $11.89(0.3$ \\
\hline 6 & $70(3.6)$ & $83(5.1)$ & $79(5.6)$ & 622 & $(0.1)$ & $432(2.9)$ & $454(4.8)$ & $11.57(0.4)$ & $11.71(0.3)$ & $11.67(0.0$ \\
\hline 9 & $68(2.5)$ & $76(8.2)$ & $70(6.8)$ & 549 & $(0.4)$ & $468(2.8)$ & $466(4.8)$ & $11.60(0.0)$ & $11.65(0.4)$ & $11.62(0.4)$ \\
\hline 10 & $77(1.7)$ & $86 \quad(5.8)$ & $78(2.9)$ & 537 & (2.9) & $465(3.2)$ & 471 & $11.67(0.0)$ & $11.69(0.3)$ & $11.60(0.6$ \\
\hline 11 & $90(4.4)$ & $95(8.3)$ & 91 (12.4) & 594 & (4.0) & $489(5.3)$ & $497(2.3)$ & $11.53(0.0)$ & $11.53(0.0)$ & 11.49 \\
\hline 12 & $57(6.0)$ & $54(1.1)$ & $56(8.5)$ & 499 & (1.0) & $423(6.6)$ & $425(6.4)$ & $11.73(0.0)$ & $11.80(0.6)$ & 11.750 .3 \\
\hline 13 & $85(4.2)$ & $81(4.5)$ & $86 \quad(5.8)$ & 611 & (4.5) & $494(1.4)$ & $514(3.8)$ & $11.53(0.0)$ & $11.60(0.0)$ & $11.53(0.0$ \\
\hline 14 & $63(4.7)$ & $59(5.4)$ & $66(7.7)$ & 509 & (5.7) & 421 & $434(5.3)$ & $11.77(0.4)$ & $11.87(0.0)$ & $11.73(0.0$ \\
\hline Mean & $82^{\mathrm{a}}$ & $84^{\mathrm{a}}$ & $85^{\mathrm{a}}$ & $601^{\mathrm{a}}$ & & $475^{\mathrm{b}}$ & $481^{\mathrm{b}}$ & $11.55^{\mathrm{a}}$ & $11.64^{\mathrm{a}}$ & $11.59^{\mathrm{a}}$ \\
\hline
\end{tabular}

${ }^{\mathrm{a}, \mathrm{b}}$ Different letters within a row for each of the 3 functional properties indicate significant differences in the functional properties between the 3 manufacturing treatments $(P<0.05)$.

${ }^{1} \mathrm{RSD}=$ Relative standard deviation (calculated in the case of TPA-Hardness values for all 3 treatments and the hot apparent viscosity as well as the time at $5000 \mathrm{cP}$ values of the 2 RVA treatments).

${ }^{2} \mathrm{RD}=$ Relative deviation from the mean (calculated in the case of hot apparent viscosity and time at $5000 \mathrm{cP}$ values of the BTS treatment).

${ }^{3} \mathrm{BTS}=$ Blentech twin-screw pilot-scale cooker.

${ }^{4}$ RVA-1 = Rapid visco analyzer-treatment 1.

${ }^{5}$ RVA-2 = Rapid visco analyzer-treatment 2 . 


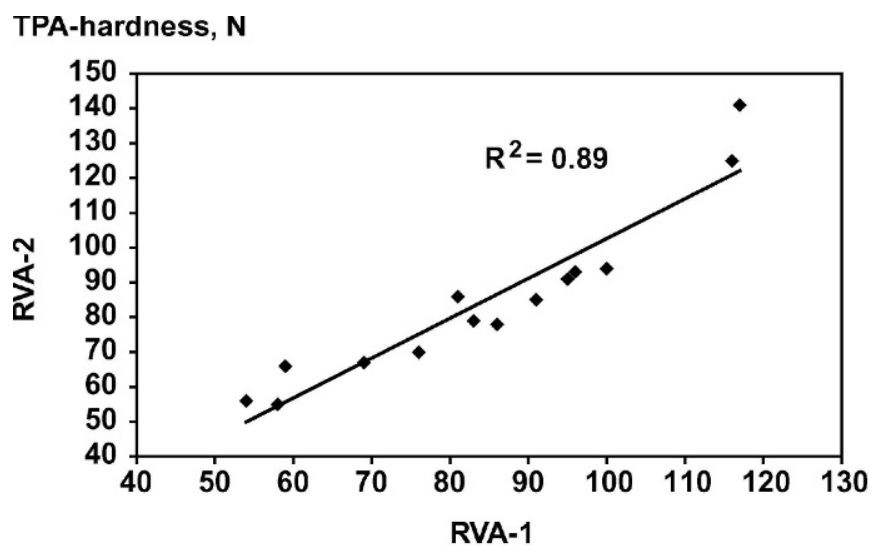

Hot apparent viscosity, cP

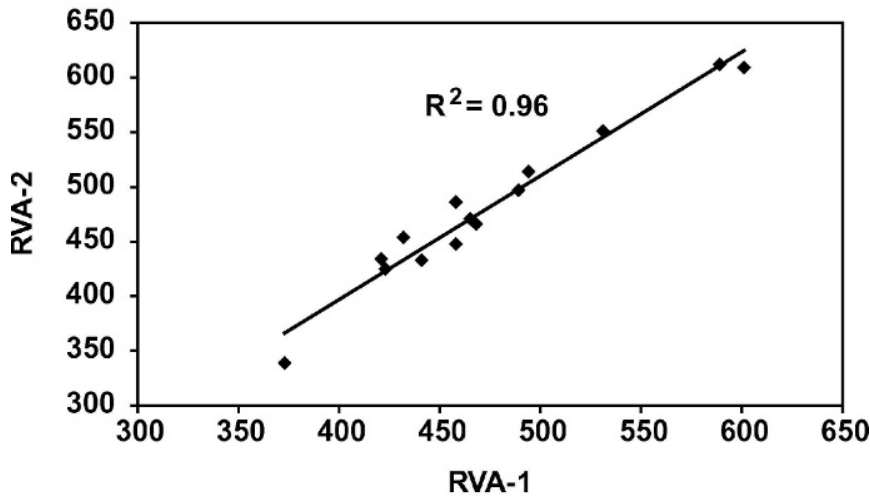

Time at $5000 \mathrm{cP}, \min$

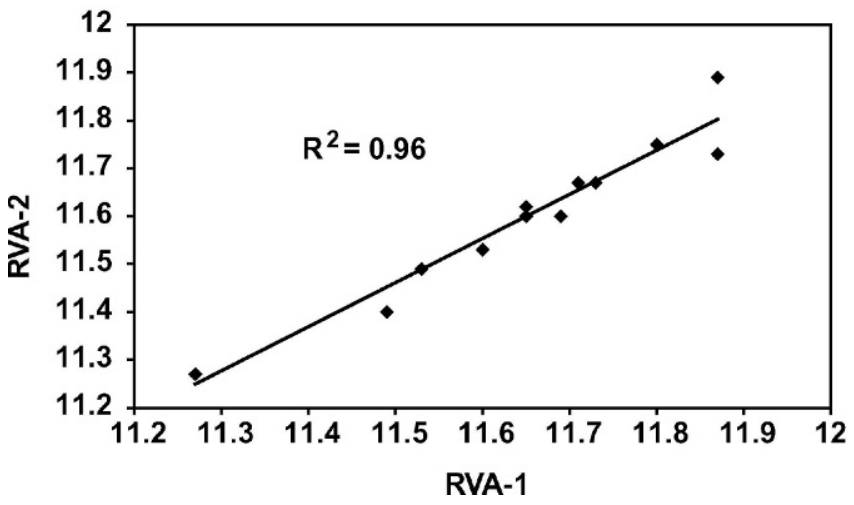

Figure 3. Simple linear regression curves (along with the $R^{2}$ values) between texture profile analysis (TPA)-hardness, hot apparent viscosity, and time at $5000 \mathrm{cP}$ values obtained for the process cheeses manufactured using RVA-1 and RVA-2 (rapid visco analyzer treatments 1 and 2).

Comparison of the RVA and pilot-scale manufacturing treatments. Figure 4 indicates the simple linear regression curves (along with the $\mathrm{R}^{2}$ value) between the 2 RVA treatments and BTS treatment for the 3 functional properties. When TPA-hardness for RVA treatments 1 and 2 were compared with BTS, $\mathrm{R}^{2}$
TPA-hardness, $\mathbf{N}$

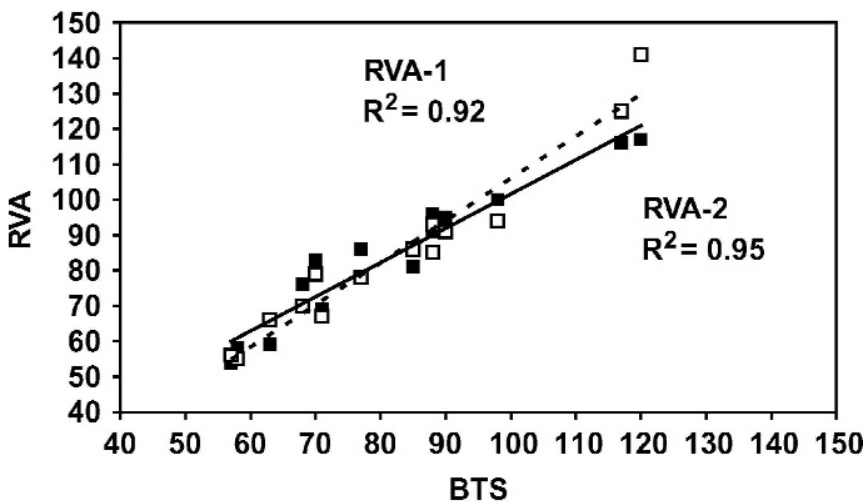

Hot apparent viscosity, cP

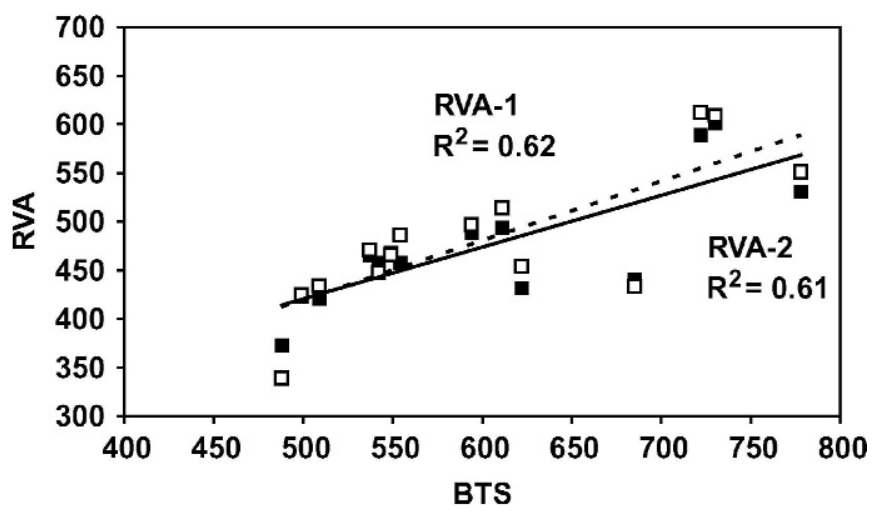

Time at $5000 \mathrm{cP}, \min$

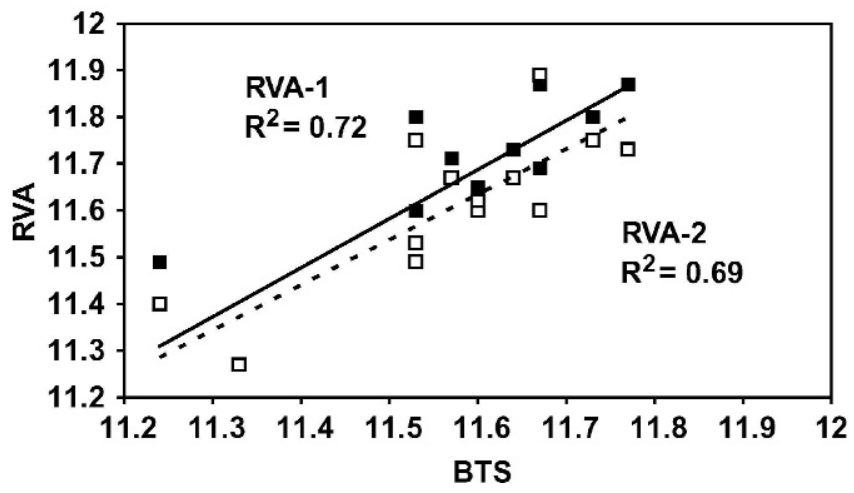

Figure 4. Simple linear regression curves (along with the $\mathrm{R}^{2}$ values) between the TPA-hardness, hot apparent viscosity and time at $5000 \mathrm{cP}$ values obtained for the process cheeses manufactured using

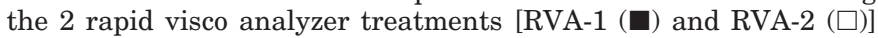
and BTS (Blentech twin-screw pilot-scale cooker treatment).

values were 0.92 and 0.95 , respectively. This indicates very high correlation between the PCF manufactured in the RVA and in the pilot plant. When the melted textural properties (hot apparent viscosity and time at $5000 \mathrm{cP}$ ) for RVA-1 and RVA-2 were compared with $\mathrm{BTS}$, the $\mathrm{R}^{2}$ values for hot apparent viscosity were 0.62 
Table 4. Mean values and $\mathrm{RSD}^{1}$ (in parentheses; $\mathrm{n}=3$ ) of the rapid visco analyzer (RVA) cook variables for the 14 pasteurized process cheese food (PCF) manufactured using RVA treatments 1 (RVA-1) and 2 (RVA-2).

\begin{tabular}{|c|c|c|c|c|}
\hline \multirow[b]{2}{*}{$\mathrm{PCF}$} & \multicolumn{2}{|c|}{ Time of emulsification, min } & \multicolumn{2}{|c|}{ End apparent viscosity, $\mathrm{cP}$} \\
\hline & RVA-1 & RVA-2 & RVA-1 & RVA-2 \\
\hline 1 & $3.67(23.1)$ & $0.80(14.5)$ & $8761(4.1)$ & 3027 (3.9) \\
\hline 2 & $2.03(4.8)$ & $0.55(7.3)$ & 4983 (1.5) & $2169(0.9)$ \\
\hline 3 & $2.96(37.8)$ & $0.55(7.3)$ & $4982(2.3)$ & $1896(2.3)$ \\
\hline 4 & $2.14(1.6)$ & $0.58(7.0)$ & $6141(4.3)$ & $2417(17.2)$ \\
\hline 5 & $1.21(13.4)$ & $0.31(11.2)$ & $3321 \quad(7.7)$ & $1475(10.0)$ \\
\hline 6 & $2.69(10.1)$ & $0.60(0.0)$ & $5713(4.7)$ & 2123 \\
\hline 7 & $2.03(2.2)$ & $0.49(7.1)$ & 3999 (3.1) & $1704(10.8)$ \\
\hline 8 & $3.61(28.7)$ & $0.58(7.0)$ & 9061 (11.4) & $3192(12.0)$ \\
\hline 9 & $1.65(12.4)$ & $0.40(0.0)$ & 4567 (1.0) & 1832 \\
\hline 10 & 2.19 (14.1) & $0.47(0.0)$ & $4859(2.2)$ & 2181 \\
\hline 11 & 2.78 (19.7) & $0.47(0.0)$ & 6025 (8.7) & 2440 \\
\hline 12 & 1.69 (1.5) & $0.42(9.5)$ & $3982(6.6)$ & 1705 \\
\hline 13 & $3.29(41.9)$ & $0.51(6.8)$ & $5985(7.4)$ & 2520 \\
\hline 14 & 1.77 (13.4) & $0.47(0.0)$ & $3929(8.1)$ & $1744(10.1)$ \\
\hline
\end{tabular}

${ }^{1} \mathrm{RSD}=$ Relative standard deviation.

and 0.61 , and values for time at $5000 \mathrm{cP}$ were 0.72 and 0.69 , respectively. Moreover, PCF manufactured in BTS had a significantly higher hot apparent viscosity compared with PCF manufactured using RVA-1 and RVA-2 (Table 3). The correlation coefficients of the melted textural properties were lower compared with the TPA-hardness data. The reason for the lower correlation in melted textural properties may be related to how quickly the samples cooled after the process cheese was manufactured in the RVA vs. BTS cooker. A study performed by Zong et al. (2004) indicated that when process cheese was cooled at a slower cooling rate, its meltability decreased. Because the PCF manufactured with the 2 RVA treatments were filled in copper cylinders of $20 \mathrm{~mm}$ diameter and $30 \mathrm{~mm}$ height and transferred to the cold store, they cooled at a faster rate than the PCF manufactured with the BTS treatment, which was filled in 1-kg boxes $(215 \mathrm{~mm} \times 70 \mathrm{~mm} \times 58 \mathrm{~mm})$. When the melted textural properties were analyzed for RVA treatments 1 and 2 and the BTS treatment, the hot apparent viscosity value for BTS was higher than for the 2 RVA treatments. These differences may be related to how samples were obtained for analysis. Subsamples from the BTS treatment were taken from 1$\mathrm{kg}$ boxes, whereas samples from the RVA treatments came from the same PCF-filled cylinders that were used for TPA analysis. Overall, there was a good correlation between the 3 functional properties of the 14 PCF manufactured with the 2 RVA processing treatments and the BTS pilot-scale treatment. These results indicate that both RVA manufacturing profiles could be used to produce process cheese similar to that produced on a pilot scale.

\section{Interpretation of Data Obtained During Process Cheese Manufacture in the RVA}

Time of emulsification. Table 4 indicates the mean values for time of emulsification of the 14 PCF formulations manufactured with RVA treatments 1 and 2 . As described by Kapoor et al. (2004), a sudden increase in viscosity (as monitored using the RVA apparent viscosity curve) is observed during the course of RVA process cheese manufacture. This increase in viscosity during RVA manufacture was used as an indicator of emulsion formation and was identified as the time of emulsification (Figures 1 and 2). Because the PCF produced with RVA-2 were manufactured at a higher temperature $\left(95^{\circ} \mathrm{C}\right)$ and a higher mixing speed, they emulsified earlier than the PCF manufactured using RVA-1. Therefore, the values for time of emulsification for the 14 PCF manufactured using RVA-1 were consistently higher than those of RVA-2. Treatment RVA-2 also had a smaller overall relative standard deviation as compared with RVA-1 with respect to the time of emulsification. The $\mathrm{R}^{2}$ values for time of emulsification of the 14 PCF were 0.65 and 0.73 with TPA-hardness, 0.62 and 0.60 with hot apparent viscosity, and 0.60 and 0.54 with time at $5000 \mathrm{cP}$ for RVA-1 and RVA-2 respectively. Although there was not a very high correlation between the time of emulsification of process cheese and its final functional properties, the data for time of emulsification may be valuable information for process cheese manufacturers and could be used to predict the ease of emulsion formation of a particular process cheese formulation during cooking.

End apparent viscosity. Table 4 also indicates the mean values for end apparent viscosity for the $14 \mathrm{PCF}$ 

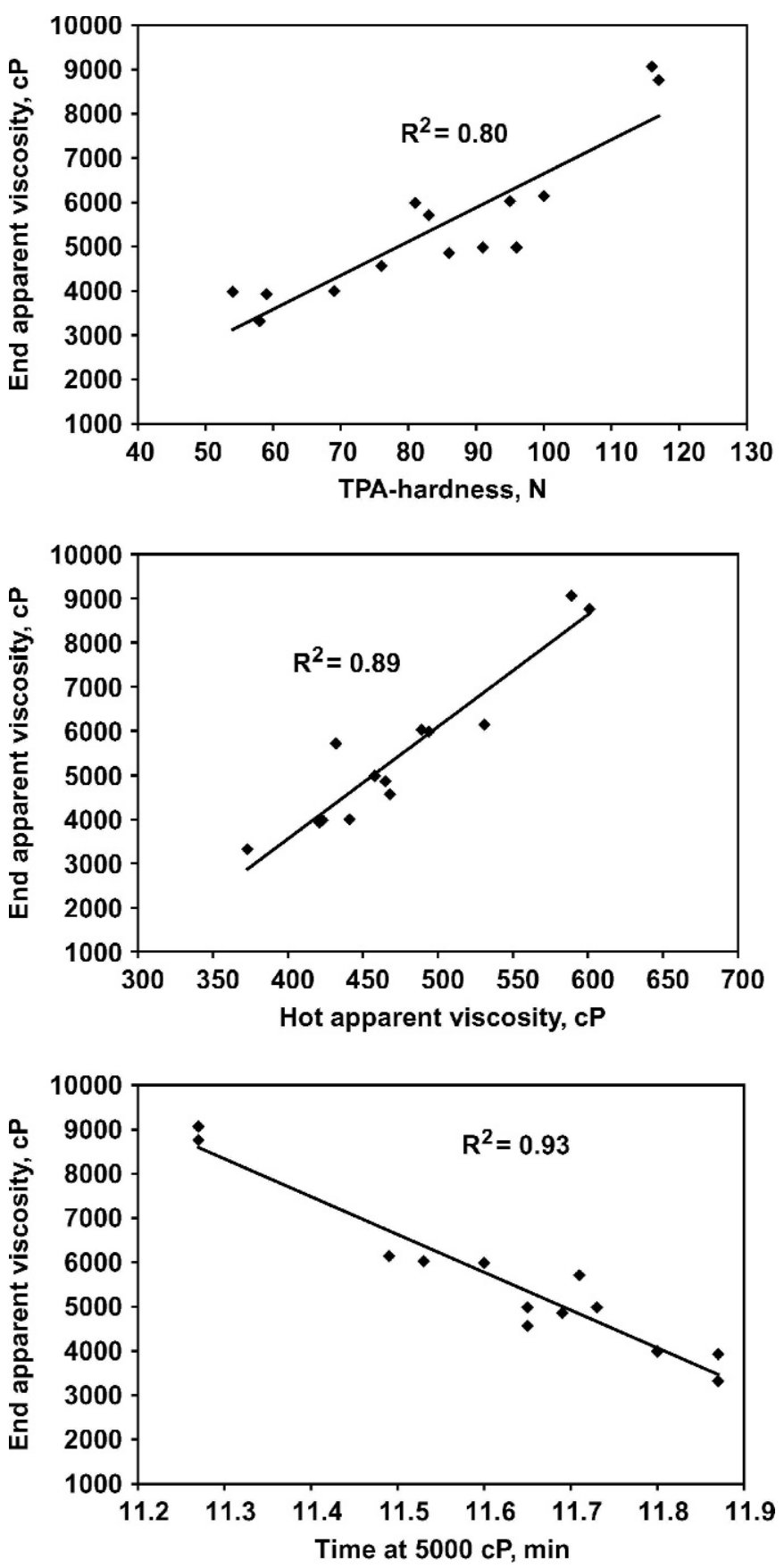

Figure 5. Simple linear regression curves (along with the $\mathrm{R}^{2}$ values) between the end apparent viscosity values and the 3 functional properties for the process cheeses manufactured using rapid visco analyzer treatment 1 .

formulations manufactured with RVA treatments 1 and 2 . As described earlier, the end apparent viscosity value was obtained by measuring the apparent viscosity of the cooked process cheese and mixing it at $160 \mathrm{rpm}$ for $1 \mathrm{~min}$ at the end of RVA manufacture. Because the PCF manufactured with RVA-2 was cooked at a higher temperature $\left(95^{\circ} \mathrm{C}\right)$ compared with RVA- $1\left(80^{\circ} \mathrm{C}\right)$, the end apparent viscosity values for RVA-2 were consistently lower than the values obtained for RVA-1. Because end apparent viscosity is a measure of process cheese flow after manufacture, it may be an effective predictor of the final functional properties of process cheese. Figures 5 and 6 indicate the simple linear regression curves (along with the $R^{2}$ value) between the end apparent viscosity and the functional properties of the 14 PCF manufactured with RVA-1 and RVA-2, respectively. The $R^{2}$ values for end apparent viscosity for the 14 PCF manufactured with RVA treatments 1 and 2 are as follows: 0.80 and 0.85 for TPA-hardness, 0.89 and 0.91 for hot apparent viscosity, and 0.93 for time at $5000 \mathrm{cP}$, respectively. Therefore, end apparent viscosity data obtained during RVA manufacture could be effectively used to predict the final functional properties of that process cheese. Consequently, it may be possible to eliminate the various tests that are used to evaluate the final functional properties of process cheese and just use the RVA process cheese manufacture profile to evaluate the functionality of process cheese.

\section{CONCLUSIONS}

Process cheese food was successfully manufactured and analyzed on a small-scale using an RVA. The data obtained during RVA manufacture of process cheese can be effectively used to predict how formulation changes affect the functional properties of the resulting process cheese. There was good correlation between the functional properties of process cheeses manufactured using the 2 RVA manufacturing profiles and the process cheeses manufactured in the pilot-scale cooker. Consequently, the modifications used in the RVA methodology, such as preblend preparation and handling, as well as standardization of RVA manufacturing conditions such as temperature, mixing speed, and time of manufacture were successful in producing process cheese with functional properties similar to the process cheese produced on a pilot scale. Therefore, the RVA can be used as a small-scale manufacturing and analysis tool for evaluating the effect of formulation and processing parameters on process cheese functional properties.

\section{ACKNOWLEDGMENTS}

The authors thank Midwest Dairy Association Inc., USA, and Dairy Management Inc., USA, for funding this project. The authors also thank Praveen Upreti, Department of Food Science and Nutrition, University of Minnesota, for manufacturing the natural cheeses used for this study, and Adrian Pollard, Department of 

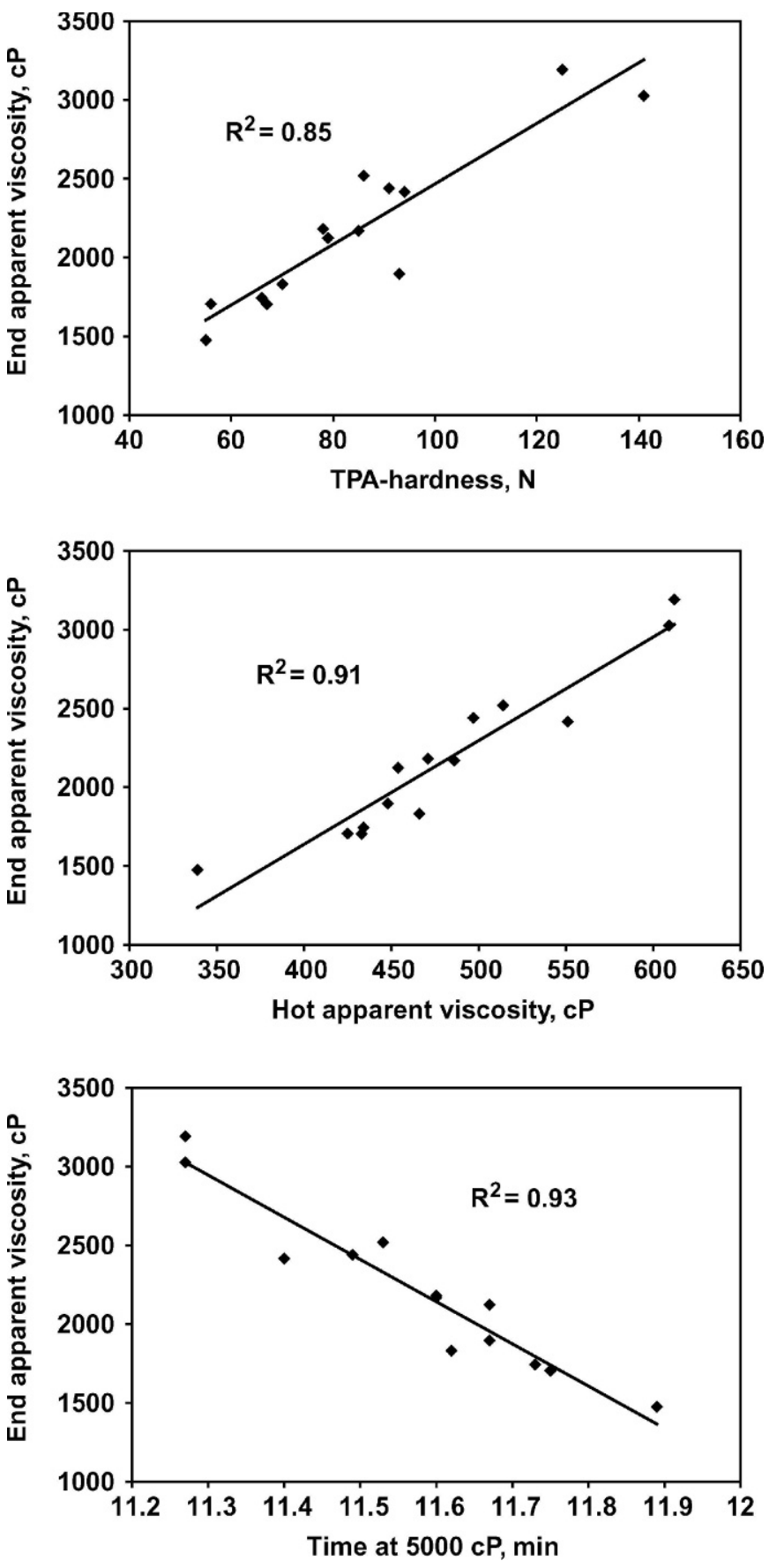

Figure 6. Simple linear regression curves (along with the $\mathrm{R}^{2}$ values) between the end apparent viscosity values and the 3 functional properties for the process cheeses manufactured using rapid visco analyzer treatment 2 .

Food Science and Nutrition, University of Minnesota, for assisting with process cheese manufacture in the RVA.

\section{REFERENCES}

Berger, W., H. Klostmeyer, K. Merkenich, and G. Uhlmann. 1998. Process Cheese Manufacture-A JOHA Guide. BK Guilini Chemie Gmbh and Co. OHG, Ladenberg, Germany.

Bradley, R. L., Jr., and M. A. Vanderwarn. 2001. Determination of moisture in cheese and cheese products. J. AOAC 84:570-592.

Breene, W. M. 1975. Application of texture profile analysis to instrumental food texture evaluation. J. Texture Stud. 6:53-82.

Caric, M., M. Gantar, and M. Kalab. 1985. Effects of emulsifying agents on the microstructure and other characteristics of process cheese-A review. Food Microstruct. 4:297-312.

Code of Federal Regulations. 2003. Section 133.169. US Dept. Health Human Services, Washington, DC.

Drake, M. A., P. D. Gerard, V. D. Truong, and C. R. Daubert. 1999. Relationship between instrumental and sensory measurements of cheese texture. J. Texture Stud. 30:451-476.

Glenn, T. A., III, C. R. Daubert, B. E. Farkas, and L. A. Stefanski. 2003. A statistical analysis of creaming variables impacting process cheese melt quality. J. Food Qual. 26:299-321.

Gupta, S. K., C. Karahdian, and R. C. Lindsay. 1984. Effect of emulsifier salts on textural and flavor properties of processed cheeses. J. Dairy Sci. 67:764-778.

Kapoor, R., P. Lehtola, and L. E. Metzger. 2004. Comparison of pilotscale and rapid visco analyzer process cheese manufacture. J. Dairy Sci. 87:2813-2821.

Lee, S. K., and H. Klostmeyer. 2001. The effect of pH on the rheological properties of reduced-fat model processed cheese spreads. Lebensm. Wiss. Technol. 34:288-292.

Lucey, J. A., M. E. Johnson, and D. S. Horne. 2003. Invited review: Perspectives on the basis of the rheology and texture properties of cheese. J. Dairy Sci. 86:2725-2743.

Marchesseau, S., E. Gastaldi, A. Lagaude, and J.-L. Cuq. 1997. Influence of $\mathrm{pH}$ on protein interactions and microstructure of process cheese. J. Dairy Sci. 80:1483-1489.

Metzger, L. E. 2003. Nutrition labeling using a computer program. Pages 1-6 in Food Analysis Laboratory Manual. S. S. Nielsen, ed. Kluwer Academic, New York, NY.

Metzger, L. E., R. Kapoor, L. A. Rosenberg, and P. Upreti. 2002. RVA: Process cheese manufacture. Aust. J. Dairy Technol. 57:136. (Abstr.)

Piska, I., and J. Štětina. 2003. Influence of cheese ripening and rate of cooling of the processed cheese mixture on rheological properties of processed cheese. J. Food Eng. 61:551-555.

Prow, L. A. 2004. Development of a melt test for process cheese spread and process cheese product using the rapid visco analyzer (RVA). M.S. Thesis, University of Minnesota, St. Paul.

Prow, L. A., and L. E. Metzger. 2005. Melt analysis of process cheese spread or product using a rapid visco analyzer. J. Dairy Sci. 88:1277-1287.

Rayan, A. A., M. Kalab, and C. A. Ernstrom. 1980. Microstructure of process cheese. Scan. Electron Microsc. III:635-643.

Sood, S. M., D. K. Gaind, and R. K. Dewan. 1979. Correlation between micelle solvation and calcium content. N.Z. J. Dairy Sci. Technol. 14:32-34.

Thomas, M. A. 1973. The Manufacture of Processed Cheese - Scientific Principles. 1st ed. New South Wales Department of Agriculture, Richmond, N.S.W., Australia.

Upreti, P., R. Kapoor, S. K. G. Purna, and L. E. Metzger. 2004. Influence of calcium, phosphorus, residual lactose, and salt-tomoisture ratio on cheese quality: Manufacture and composition. J. Dairy Sci. 87(Suppl. 1):288. (Abstr.)

Vakaleris, D. G., N. F. Olson, and W. V. Price. 1962. Effects of proteolysis of natural cheese on body and melting properties of pasteurized process cheese spread. J. Dairy Sci. 45:492-494.

Zehren, V. L., and D. D. Nusbaum. 2000. Processed Cheese. 2nd ed. Cheese Reporter Publishing Co. Inc., Madison, WI.

Zong, Q., C. R. Daubert, and B. E. Farkas. 2004. Cooling effects on processed cheese functionality. J. Food Process Eng. 27:392-412. 